\title{
ACTRIS \\ Aerosol, Clouds and Trace gases Research InfrastruCture \\ Gelsomina Pappalardo
}

\author{
Consiglio Nazionale delle Ricerche - Istituto di Metodologie per l'Analisi Ambientale CNR-IMAA, C.da \\ S. Loja, I-85050 Tito Scalo, Potenza, Italy,*Email: gelsomina.pappalardo@imaa.cnr.it
}

\begin{abstract}
The Aerosols, Clouds and Trace gases Research Infrastructure (ACTRIS) is a distributed infrastructure dedicated to high-quality observation of aerosols, clouds, trace gases and exploration of their interactions. It will deliver precision data, services and procedures regarding the 4D variability of clouds, short-lived atmospheric species and the physical, optical and chemical properties of aerosols to improve the current capacity to analyse, understand and predict past, current and future evolution of the atmospheric environment.
\end{abstract}

\section{INTRODUCTION}

Short-lived atmospheric components - aerosols, clouds, trace gases - have a residence time in the atmosphere from hours to few weeks, which differentiates them from long-lived greenhouse gases. The short lifetimes make their concentrations highly variable in time and space and involve fast processes. They are recognised to be among the most significant anthropogenic pollutants affecting Earth's radiation balance and the largest source of uncertainty in terms of radiative forcing impact [1]. In parallel, shortlived atmospheric compounds have recognized adverse health effects at concentrations typically found across Europe and potentially lead to more than 400.000 premature deaths annually in the EU28 [2]. Information on concentrations and distributions of aerosols and trace gases is therefore required to reduce air pollution and related adverse effects on health and ecosystems [3]. ACTRIS (www.actris.eu) addresses these challenges by operating at National Facilities a combination of near-surface and remote-sensing systems including: near surface measurements of aerosols and short-lived trace gases, vertically resolved measurements of aerosols, vertically resolved measurements of clouds and precipitation, profile and column observations of short-lived trace gases and ancillary measurements of meteorological and radiation quantities. ACTRIS also includes exploratory platforms at the national level. The observation platforms are often components of European or international networks [4]. ACTRIS relies on appropriate Central Facilities - Calibration Centres, Data Centre, Head Office - that ensure compliance with standard operating procedures and/or quality protocols to provide harmonized, reliable, and documented observational data. The data curation and storage services are handled by a dedicated Central Facility, the ACTRIS Data Centre.

ACTRIS serves a vast community of users working on observations, experiments, models, satellite data, analysis and predicting systems and offers access to advanced technological platforms for exploration of the relevant atmospheric processes in the fields of climate change and air quality.

\section{$2 \quad$ ACTRIS Research Infrastructure}

The Research Infrastructure ACTRIS is the panEuropean initiative that consolidates strategies amongst European partners for observations of aerosols, clouds, and trace gases. The infrastructure is unique in providing the 4Dvariability of clouds and of the physical, optical and chemical properties of short-lived atmospheric species, in particular those involved in climate forcing.

The primary objective of ACTRIS is to provide the 4D-variability of clouds and of the physical, optical and chemical properties of short-lived atmospheric species, from the surface throughout 
the troposphere to the stratosphere, with the required level of precision, coherence and integration. The second objective is to provide effective access to this information and the means to more efficiently use the complex and multiscale ACTRIS parameters serving a vast community of users working on models, satellite retrievals, and analysis and forecast systems. The third objective is to raise the level of technology used in the RI and the quality of services offered to the community of users, involving partners from the private sector. Finally, the fourth objective of ACTRIS is to promote training of operators and users and enhance the linkage between research, education and innovation in the field of atmospheric science.

ACTRIS is composed of several connected elements:

- National Facilities (NFs) (observation platforms, stationary and mobile exploratory platforms hosted and operated at the national level) located both within Europe and globally, documenting with high precision and reliability the 4Dvariability of short-lived atmospheric species, in particular those involved in climate forcing and the processes driving their life-cycle;

- Central Facilities (CFs): Calibration Centres, Data Centre, Head Office hosted and operated at the European level.

ACTRIS engages the National Facilities with highly standardized and coordinated procedures. The Central Facilities are required to ensure that all data are produced, treated and qualitycontrolled with specified procedures, properly archived for long-term usage, and accessible in a timely manner to all users. Central Facilities are responsible for the definition of ACTRIS data products, including definition of quality requirements, format and nature of delivery (near real time or consolidated), flagging and development of value-added products. Central Facilities are fundamental to provide the access to the ACTRIS services, organising the right level of training and education, both within and outside the RI, and delivering tailored services for various users, scientific community, space agencies, COPERNICUS [5] and the private sector.

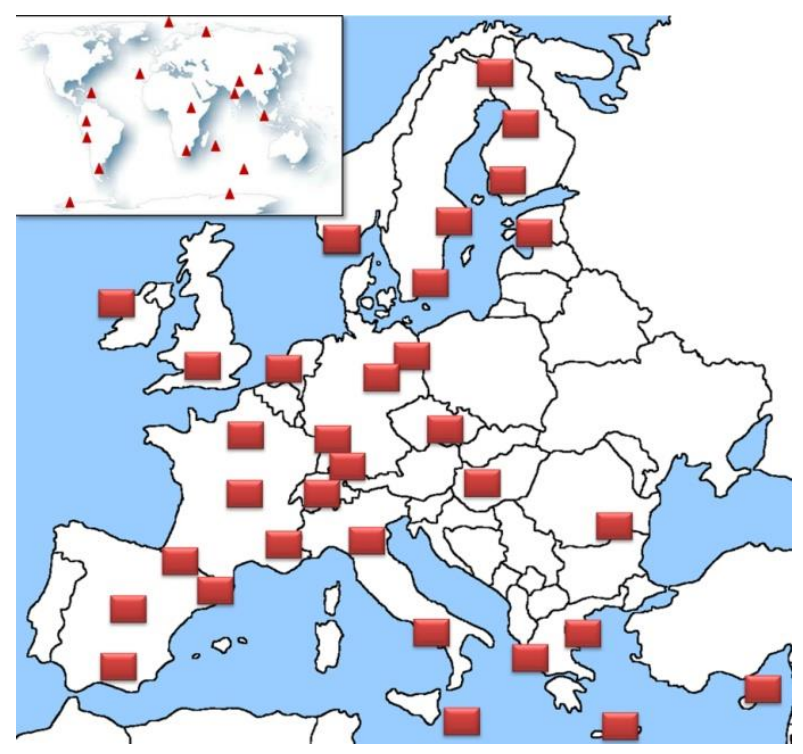

Figure 1 Distribution of ACTRIS observation stations

More specifically, Calibration Centres provide the infrastructure with: a) Standard operation procedures and best practices; b) Qualityassurance criteria; c) Intercomparison of instruments and procedures; d) Development and testing of new instrumentation for variables that are not yet accessible at the required sensitivity/accuracy; e) Training of RI managers, staff, data providers, and users.

The data curation and repository services, including data management and necessary development work on, workflow documentation, metadata issues, etc., are handled by the ACTRIS Data Centre (DC). All primary data and addedvalue data products are made available to the users via the ACTRIS data portal. ACTRIS follows the open research data initiative of the European Union, making data discoverable (DOI identification), accessible (via open licence) and assessable (via necessary documentation and description). These data products are made interoperable, adhere to specific quality standards and are free of charge.

Besides data services and access to data products, ACTRIS will also offer physical and remote access to Calibration Centres and physical access 
to selected National Facilities. Access will be handled by the ACTRIS Service and Access Management Unit (SAMU) which is the entry point to coordinate access to the users to the different services granted through a per review process. SAMU is integrated within the ACTRIS Head Office (HO) which coordinates the research infrastructure operations, facilitates the strategic decision-making, and represents ACTRIS.

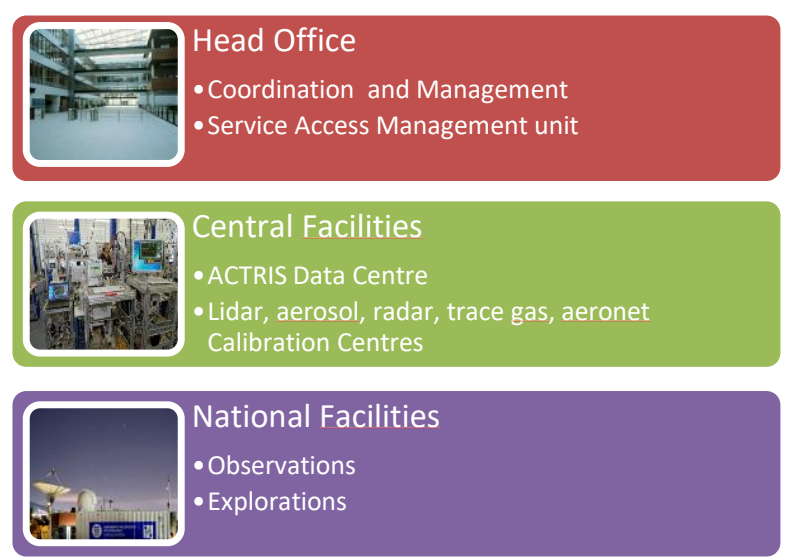

Figure 2 ACTRIS Structure

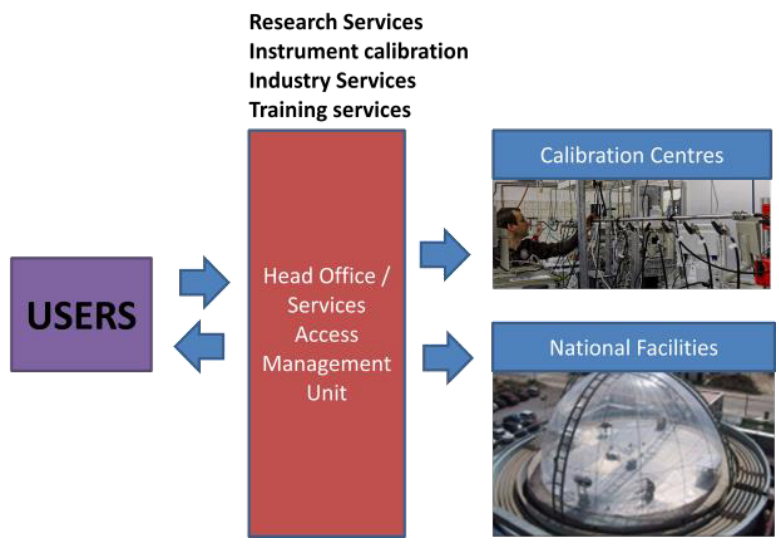

Figure 3 Physical access related ACTRIS services

\section{Towards the Implementation}

ACTRIS, as research infrastructure, was listed in 2016 among the ESFRI projects (www.esfri.eu) [6], and has just started the preparation phase but it results from long-term collaborative work of the atmospheric science community through a series of European projects (EARLINET, EUSAAR,
EARLINET-ASOS, CloudNet, EUROCHAMP 2020, ACTRIS 1 and ACTRIS 2) that started in 2000 [7, 8, 9]. The gradual shift towards the construction phase of the research infrastructure is foreseen in 2019- 2021 planning the commissioning phase in 2021-2022. ACTRIS will be fully operational in 2025 .

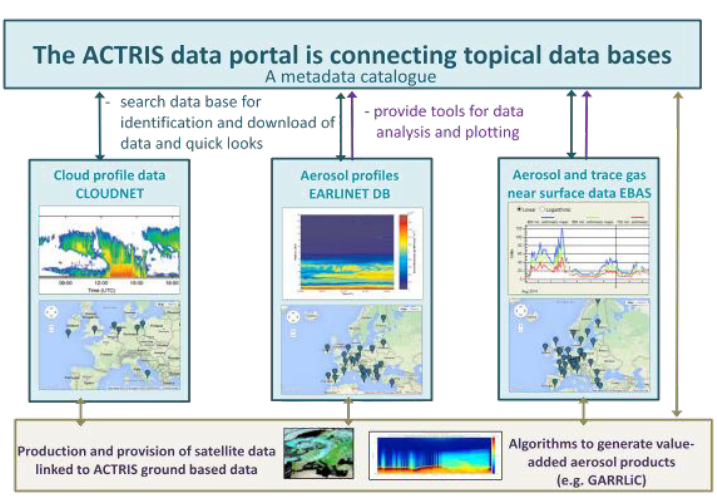

Figure 4 ACTRIS data portal

The implementation of ACTRIS as a research infrastructure is funded through the ACTRIS Preparatory Phase project devoted to develop the organizational, operational and strategic frameworks of the RI. The work includes legal, governance, financial, technical, strategic, and administrative aspects. The main outcomes of PPP are signature-ready documents for establishment of a legal entity with well-defined operations and a sound business plan.

More technical and scientific aspects are supported through the ACTRIS 2 project which addresses the scope of integrating state-of-the-art European ground-based stations for long-term observations of aerosols, clouds and short lived gases. It consolidates and improves services offered within FP7 funded Integrated Infrastructures Initiative ACTRIS (2011-2015). ACTRIS-2 takes up the overarching objectives of ACTRIS to further integrate the European groundbased stations and to construct a user-oriented RI, unique in the EU-RI landscape, for aerosols, clouds, and short-lived gas-phase species. One of the key activities within the project is the provision of access to a large number of ACTRIS2 services, implemented through its virtual and trans-national access programme (TNA), 
comprising wide and open access to high-quality information, tools and services through the ACTRIS Data Centre, hands-on access to a large number of ground-based observing platforms and advanced instrumentation, and physical and remote access to thematic calibration centres for instrument testing and development, quality assurance, training and best practices, and international collaboration.

Eighteen world-class observational facilities, unique in Europe and representing a variety of environments and air mass types, offer access to comprehensive measurement programmes and cutting-edge research, scientific campaigns, intercomparisons, and training capabilities for exploitation of state-of-the art resources, knowledge, and expertise. The observational sites comprise historical sites, operational since decades with long records and experience of access provision, and new sites for novel research opportunities.

The calibration facilities constitute multi-national installations and are globally unparalleled, being beneficial not only to the entire scientific communities, but also to users from the industrial sector and operational networks, and offer access and services to:

- the Lidar Calibration Centre ( $\mathrm{LiCal}$ ) for testing and calibration of lidars and ceilometers, including characterization and optimization of single components and assessment of whole system performances;

- the AERONET-Europe Calibration facility for calibration and standards maintenance service for sun/sky/polar/moon photometers, complementing the NASA AERONET programme for routine, real-time, and highquality aerosol column integrated properties;

- the European Centre for Aerosol Calibration (ECAC) for calibration and quality assurance of high quality physical, optical, and chemical in-situ aerosol measurements, instrument audits and capacity building.

The Transnational Access program for ACTRIS and the various opportunities are described in more detail at www.actris.eu.

\section{ACKNOWLEDGEMENTS}

21 EU or associated Countries are supporting ACTRIS with a total of more than 120 research performing organizations involved.

The financial support for ACTRIS by the European Union's Horizon 2020 research and innovation programme under grant agreement no. 654169 and no. 739530 is gratefully acknowledged.

\section{References}

[1] IPCC 2013 WGI AR5 Chapter.

[2] European Environmental Agency, "Air quality in Europe - 2014 report”, EEA Report No $5 / 2014$.

[3] WHO, Review of Evidence on Health Aspects of Air Pollution - REVIHAAP Project, Technical Report, World Health Organization Geneva, 2013, http://www.euro.who.int/_data/assets/pdf_file/ 0004/193108/REVIHAAP-Final-technicalreport-final-version.pdf.

[4] Lund Myhre, C, and Baltensperger, U, et al., 2012: Recommendations for a Composite Surface-Based Aerosol Network, GAW Report n. 207, www.wmo-gaw-wcc-aerosolphysics.org/files/gaw-207.pdf.

[5] COPERNICUS www.copernicus.eu.

[6] ESFRI roadmap 2016 - Strategy Report on Research Infrastructures, www.esfri.eu.

[7] Pappalardo, G., et al., 2014: EARLINET: towards an advanced sustainable European aerosol lidar network, Atmos. Meas. Tech., 7, 2389-2409, doi:10.5194/amt-7-2389-2014, 2014.

[8] Laj P., et al., 2009: Measuring Atmospheric Composition Changes, Atmospheric Environment, Vol. 43, No. 33, pp. 5351-5414, doi:10.1016/j.atmosenv.2009.08.020.

[9] Illingworth, A. J. et al., 2007: Cloudnet Continuous Evaluation of Cloud Profiles in Seven Operational Models Using GroundBased Observations, BAMS, doi: http://dx.doi.org/10.1175/BAMS-88-6-883. 